\title{
YTHDC1 gene polymorphisms and neuroblastoma susceptibility in Chinese children
}

\author{
Yong $\mathrm{Li}^{1,2}$, Tongyi Lu ${ }^{3}$, Jian Wang ${ }^{1}$, Zhenjian Zhuo ${ }^{3}$, Lei Miao ${ }^{3}$, Zhonghua Yang ${ }^{4}$, Jiao Zhang ${ }^{5}$, \\ Jiwen Cheng ${ }^{6}$, Haixia Zhou', Suhong $\mathrm{Li}^{8}$, $\mathrm{Li} \mathrm{Li}^{9}$, Jing $\mathrm{He}^{3}, \mathrm{Aiwu} \mathrm{Li}^{1}$ \\ ${ }^{1}$ Department of Pediatric Surgery, Qilu Hospital, Cheeloo College of Medicine, Shandong University, Jinan 250012, \\ Shandong, China \\ ${ }^{2}$ Department of Pediatric Surgery, Hunan Children's Hospital, Changsha 410004, Hunan, China \\ ${ }^{3}$ Department of Pediatric Surgery, Guangzhou Institute of Pediatrics, Guangdong Provincial Key Laboratory of \\ Research in Structural Birth Defect Disease, Guangzhou Women and Children's Medical Center, Guangzhou \\ Medical University, Guangzhou 510623, Guangdong, China \\ ${ }^{4}$ Department of Pediatric Surgery, Shengjing Hospital of China Medical University, Shenyang 110004, Liaoning, China \\ ${ }^{5}$ Department of Pediatric Surgery, The First Affiliated Hospital of Zhengzhou University, Zhengzhou 450052, \\ Henan, China \\ ${ }^{6}$ Department of Pediatric Surgery, The Second Affiliated Hospital of Xi'an Jiaotong University, Xi'an 710004, \\ Shaanxi, China \\ ${ }^{7}$ Department of Hematology, The Second Affiliated Hospital and Yuying Children's Hospital of Wenzhou Medical \\ University, Wenzhou 325027, Zhejiang, China \\ ${ }^{8}$ Department of Pathology, Children Hospital and Women Health Center of Shanxi, Taiyuan 030013, Shannxi, China \\ ${ }^{9}$ Kunming Key Laboratory of Children Infection and Immunity, Yunnan Key Laboratory of Children's Major Disease \\ Research, Yunnan Institute of Pediatrics Research, Yunnan Medical Center for Pediatric Diseases, Kunming \\ Children's Hospital, Kunming 650228, Yunnan, China
}

Correspondence to: Aiwu Li, Jing He; email: liaiwuxie@aliyun.com, https://orcid.org/0000-0002-4504-8687,

hejing198374@gmail.com, https://orcid.org/0000-0002-1954-2892

Keywords: neuroblastoma, $\mathrm{m}^{6} \mathrm{~A}, \mathrm{YTHDC1}$, polymorphism, susceptibility

Received: September 13, 2021 Accepted: December 2, $2021 \quad$ Published: December 12, 2021

Copyright: (C) $2021 \mathrm{Li}$ et al. This is an open access article distributed under the terms of the Creative Commons Attribution License (CC BY 3.0), which permits unrestricted use, distribution, and reproduction in any medium, provided the original author and source are credited.

\section{ABSTRACT}

Neuroblastoma (NB) is the most common extracranial tumor in children. YTHDC1, a member of RNA methylation modification binding proteins, plays critical roles in tumor occurrence and metastasis. However, it is unclear whether YTHDC1 gene polymorphisms are related to NB susceptibility. Herein, we aimed to evaluate the association between YTHDC1 gene polymorphisms (rs2293596 T>C, rs2293595 T>C, rs3813832 T>C) and susceptibility of NB by logistic regression models. In this eight-center case-control study, 898 patients with NB and 1734 healthy controls were genotyped by TaqMan assay. The results showed that rs3813832 TC genotype could significantly reduce the susceptibility of NB compared with the TT genotype [adjusted odds ratio (AOR) = $0.81,95 \%$ confidence interval $(\mathrm{Cl})=0.68-0.96, P=0.018$ ]. Combined genotype analysis revealed that individuals with 3 protective genotypes had a prominently lower NB risk than those with 0-2 protective genotypes (AOR = $0.80,95 \% \mathrm{Cl}=0.68-0.94, P=0.006)$. The stratified analysis also demonstrated the protective effect of rs $3813832 \mathrm{TC} / \mathrm{CC}$ and 3 protective genotypes in certain subgroups. Further functional experiments revealed that YTHDC1 siRNA-554, targeting the area near the rs3813832 $\mathrm{T}>\mathrm{C}$ polymorphism site, could observably inhibit 


\section{the proliferation and migration of NB cells. In conclusion, our findings highlight the involvement of YTHDC1 gene and its genetic variants in the etiology of NB.}

\section{INTRODUCTION}

Neuroblastoma (NB) is the most common extracranial solid tumor in children, accounting for $8 \%$ of all pediatric malignancies [1]. The mortality rate of NB is $0.85-1.1$ cases per 100,000 children in the world [2]. Most of the low-risk NB patients resolve spontaneously without chemotherapy [3]. However, high-risk patients, accounting for nearly $50 \%$ of $\mathrm{NB}$, have been extensively metastatic at the time of diagnosis. Despite various treatments such as surgery, chemotherapy, radiotherapy, and immunotherapy, the survival rate is still less than $40 \%$ [4]. Unfortunately, the pathogenesis of NB has not yet been fully understood $[5,6]$. Studies have found that about $1-2 \%$ of NB cases are familial [2]. PHOX2B [7] or $A L K$ [8] gene mutations are considered to be the main cause of familial NB. However, sporadic neuroblastoma is the main form of NB [9]. Increasing evidence shows that genetic variants play a key role in the development of NB [10-12]. In recent years, several NB susceptibility loci have been identified through genome-wide association studies (GWASs), such as BARD1 [13], LMOI [14], HACEl [15], TP53 [16], CASC15 [17], MLF1 [18], and $C D K N 1 B$ [19]. Moreover, many polymorphisms were also identified to influence chemotherapy and outcome in patients with neuroblastoma $[20,21]$. The identification of these susceptible loci has deepened the understanding of the pathogenesis of NB [22, 23]. However, more gene single nucleotide polymorphisms (SNPs) involved in the process of tumorigenesis await to be revealed.

N6-methyladenosine $\left(\mathrm{m}^{6} \mathrm{~A}\right)$ is the most common and abundant post-transcriptional modification of eukaryotic mRNA [24, 25]. The formation of $\mathrm{m}^{6} \mathrm{~A}$ is dynamically converted by methyltransferase complexes ("writers"; METTL3, METTL14, and WTAP), demethylases ("erasers"; FTO and ALKBH5), and binding proteins ("readers"; YTHDF 1/2/3, YTHDC1) [26, 27]. Recently, it has been confirmed that $\mathrm{m}^{6} \mathrm{~A}$ modified disorders are involved in human carcinogenesis, including osteosarcoma [28], glioblastoma [29], colorectal cancer [30], acute myeloid leukemia [31], gastric cancer [32], glioma [33], and bladder cancer [34]. The abnormal modification level of $\mathrm{m}^{6} \mathrm{~A}$ may affect the individual's cancer susceptibility [35]. YTH domain contains protein 1 (YTHDC1), an important $\mathrm{m}^{6} \mathrm{~A}$ recognition protein, is involved in mRNA splicing and the export of methylated mRNAs [36, 37], but its role has not yet been deeply understood.
Considering the evidence that $\mathrm{m}^{6} \mathrm{~A}$ is closely related to tumorigenesis and metastasis, we speculate that there may be a significant correlation between the genetic variation of $\mathrm{m}^{6} \mathrm{~A}$ modified gene $Y T H D C 1$ and the risk of NB. Therefore, we performed this study by recruiting $898 \mathrm{NB}$ patients and 1734 controls to explore the relationship between YTHDC1 SNPs and NB risk in Chinese children.

\section{RESULTS}

\section{Association between YTHDC1 gene polymorphisms and NB susceptibility}

In this study, $896 \mathrm{NB}$ cases and 1733 controls were successfully genotyped. The three polymorphisms of YTHDC1 were consistent with Hardy-Weinberg equilibrium (HWE) $(P=0.696$ for rs $2293596 \mathrm{~T}>\mathrm{C}, P=$ 0.556 for $\mathrm{rs} 2293595 \mathrm{~T}>\mathrm{C}, P=0.968$ for $\mathrm{rs} 3813832$ $\mathrm{T}>\mathrm{C}$ ). The genotype distribution frequencies of case and control groups were shown in Table 1 . The results showed that in the rs3813832 $\mathrm{T}>\mathrm{C}$ polymorphism, relative to the TT genotype, TC genotype could significantly reduce the susceptibility of NB [adjusted odds ratio $(\mathrm{AOR})=0.81,95 \%$ confidence interval $(\mathrm{CI})=$ $0.68-0.96, P=0.018]$. In addition, we used rs 2293596 TT/TC, rs2293595 TC/CC, or rs3813832 TC/CC as protective genotypes to further investigate the combined effect of these three SNPs. The combined genotype analysis revealed that individuals carrying 3 protective genotypes had a prominent lower risk of NB compared with individuals carrying $0-2$ protective genotypes $(\mathrm{AOR}=0.80,95 \% \mathrm{CI}=0.68-0.94, P=0.006)$.

\section{Stratification analysis}

Subsequently, we conducted a stratified analysis based on age, gender, sites of origin, and clinical stage to further explore the relationship between $Y T H D C 1$ gene SNPs (rs2293596 T>C, rs2293595 T>C and rs3813832 $\mathrm{T}>\mathrm{C}$ ) and the risk of NB (Table 2). In the subgroup of clinical stage III + IV, the rs3813832 TC/CC genotype carriers suffer from a relatively lower risk of NB (AOR $=0.77,95 \% \mathrm{CI}=0.62-0.96, P=0.022)$. In addition, individuals with 3 protective genotypes had an observably decreased risk of $\mathrm{NB}(\mathrm{AOR}=0.80,95 \% \mathrm{CI}$ $=0.65-0.98, P=0.032)$ in subgroup of children over 18 months of age. As to the participants' gender, we found that male carrying the 3 protective genotypes also showed a lower NB risk (AOR $=0.77,95 \% \mathrm{CI}=0.62$ $0.96, P=0.021)$. From the sites of origin, individuals 
Table 1. Association between YTHDC1 gene polymorphisms and neuroblastoma risk.

\begin{tabular}{|c|c|c|c|c|c|c|c|}
\hline Genotype & $\begin{array}{c}\text { Cases } \\
(N=896)\end{array}$ & $\begin{array}{c}\text { Controls } \\
(N=1733)\end{array}$ & $P^{\mathbf{a}}$ & $\begin{array}{l}\text { Crude OR } \\
\text { (95\% CI) }\end{array}$ & $P$ & $\begin{array}{c}\text { Adjusted OR } \\
\left(_{(95 \%} \text { CI }\right)^{b}\end{array}$ & $P^{\mathbf{b}}$ \\
\hline \multicolumn{8}{|c|}{$\mathrm{rs} 2293596 \mathrm{~T}>\mathrm{C}(\mathrm{HWE}=0.696)$} \\
\hline $\mathrm{TT}$ & $580(64.73)$ & $1144(66.01)$ & & 1.00 & & 1.00 & \\
\hline $\mathrm{TC}$ & $272(30.36)$ & $525(30.29)$ & & $1.02(0.86-1.22)$ & 0.811 & $1.03(0.86-1.23)$ & 0.778 \\
\hline $\mathrm{CC}$ & $44(4.91)$ & $64(3.69)$ & & $1.36(0.91-2.02)$ & 0.132 & $1.36(0.91-2.02)$ & 0.130 \\
\hline Additive & & & 0.283 & $1.08(0.94-1.25)$ & 0.283 & $1.08(0.94-1.25)$ & 0.267 \\
\hline Dominant & $316(35.27)$ & $589(33.99)$ & 0.513 & $1.06(0.89-1.25)$ & 0.511 & $1.06(0.90-1.26)$ & 0.486 \\
\hline Recessive & $852(95.09)$ & $1669(96.31)$ & 0.136 & $1.35(0.91-1.99)$ & 0.137 & $1.35(0.91-2.00)$ & 0.137 \\
\hline \multicolumn{8}{|c|}{$\mathrm{rs} 2293595 \mathrm{~T}>\mathrm{C}(\mathrm{HWE}=0.556)$} \\
\hline $\mathrm{TT}$ & $343(38.28)$ & $601(34.68)$ & & 1.00 & & 1.00 & \\
\hline $\mathrm{TC}$ & $411(45.87)$ & $829(47.84)$ & & $0.87(0.73-1.04)$ & 0.121 & $0.86(0.72-1.03)$ & 0.102 \\
\hline $\mathrm{CC}$ & $142(15.85)$ & $303(17.48)$ & & $0.82(0.65-1.04)$ & 0.107 & $0.82(0.65-1.04)$ & 0.107 \\
\hline Additive & & & 0.070 & $0.90(0.80-1.01)$ & 0.070 & $0.90(0.80-1.01)$ & 0.067 \\
\hline Dominant & $553(61.72)$ & $1132(65.32)$ & 0.068 & $0.86(0.72-1.01)$ & 0.068 & $0.85(0.72-1.01)$ & 0.059 \\
\hline Recessive & $754(84.15)$ & $1430(82.52)$ & 0.289 & $0.89(0.72-1.11)$ & 0.289 & $0.89(0.72-1.11)$ & 0.309 \\
\hline \multicolumn{8}{|c|}{$\mathrm{rs} 3813832 \mathrm{~T}>\mathrm{C}(\mathrm{HWE}=0.968)$} \\
\hline $\mathrm{TT}$ & $499(55.69)$ & $902(52.05)$ & & 1.00 & & 1.00 & \\
\hline $\mathrm{TC}$ & $314(35.04)$ & $697(40.22)$ & & $0.81(0.69-0.97)$ & 0.020 & $0.81(0.68-0.96)$ & 0.018 \\
\hline $\mathrm{CC}$ & $83(9.26)$ & $134(7.73)$ & & $1.12(0.83-1.50)$ & 0.452 & $1.13(0.84-1.52)$ & 0.403 \\
\hline Additive & & & 0.424 & $0.95(0.84-1.08)$ & 0.424 & $0.95(0.84-1.08)$ & 0.446 \\
\hline Dominant & $397(44.31)$ & $831(47.95)$ & 0.076 & $0.86(0.73-1.02)$ & 0.076 & $0.86(0.73-1.02)$ & 0.075 \\
\hline Recessive & $813(90.74)$ & $1599(92.27)$ & 0.176 & $1.22(0.92-1.62)$ & 0.177 & $1.24(0.93-1.65)$ & 0.148 \\
\hline \multicolumn{8}{|c|}{ Combined effect of protective genotypes ${ }^{c}$} \\
\hline $0-2$ & $428(47.77)$ & $735(42.41)$ & & 1.00 & & 1.00 & \\
\hline 3 & $468(52.23)$ & $998(57.59)$ & 0.009 & $0.81(0.69-0.95)$ & 0.008 & $0.80(0.68-0.94)$ & 0.006 \\
\hline
\end{tabular}

Abbreviations: OR: odds ratio; $\mathrm{Cl}$ : confidence interval; HWE: Hardy-Weinberg equilibrium. ${ }^{\mathrm{a}} \chi^{2}$ test for genotype distributions

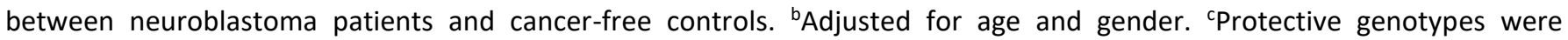
rs2293596 TT/TC, rs2293595 TC/CC and rs968697 TC/CC.

with 3 protective genotypes were less likely to have NB that original from mediastinum $(\mathrm{AOR}=0.67,95 \% \mathrm{CI}=$ $0.51-0.90, P=0.007)$. In terms of clinical stage, individuals carrying 3 protective genotypes displayed a weak susceptibility at clinical stages I + II + 4s (AOR = $0.78,95 \% \mathrm{CI}=0.64-0.96, P=0.019)$ and III $+\mathrm{IV}$ $(\mathrm{AOR}=0.77,95 \% \mathrm{CI}=0.62-0.97, P=0.023)$.

\section{Knockdown of YTHDC1 significantly inhibits proliferation of neuroblastoma cells}

SK-N-BE (2) and SK-N-SH cells transfected with YTHDC1 siRNAs (siRNA-NC, siRNA-488, siRNA554, and siRNA-702) were collected and lysed for Western blotting after $48 \mathrm{~h}$ (Figure 1A). The results showed that the expression level of YTHDC1 in SK-N-
BE (2) cells transfected with siRNA-488/siRNA554/siRNA-702 was about $50 \%(P<0.05) / 35 \%(P<$ $0.01) / 42 \%(P<0.05)$ compared with control group (Figure 1B). In SK-N-SH cells transfected with siRNA488/siRNA-554/siRNA-702, the expression level YTHDC1 was about $66 \%(P>0.05) / 39 \%(P<$ $0.01) / 88 \%(P>0.05)$. These results showed that YTHDC1 siRNA could significantly reduce the expression of YTHDC1 in SK-N-BE (2) and SK-N-SH cells.

CCK-8 assay was used to evaluate the cell viability of SK-N-BE (2) and SK-N-SH transfected with YTHDCI siRNAs (Figure 2A, 2B). The results showed that the activities of SK-N-BE (2) and SK-N-SH cells transfected with siRNA-488 were not obviously 
Table 2. Stratification analysis for association between YTHDC1 gene genotypes and neuroblastoma susceptibility.

\begin{tabular}{|c|c|c|c|c|c|c|c|c|c|c|c|c|}
\hline \multirow{2}{*}{ Variables } & \multicolumn{2}{|c|}{$\begin{array}{c}\text { rs2293595 } \\
\text { (case/control) }\end{array}$} & \multirow{2}{*}{$\begin{array}{c}\text { AOR } \\
(95 \% \text { CI })^{\mathrm{a}}\end{array}$} & \multirow[t]{2}{*}{$P^{\mathrm{a}}$} & \multicolumn{2}{|c|}{$\begin{array}{c}\text { rs3813832 } \\
\text { (case/control) }\end{array}$} & \multirow{2}{*}{$\begin{array}{c}\text { AOR } \\
(95 \% \text { CI })^{\mathrm{a}}\end{array}$} & \multirow[t]{2}{*}{$P^{\mathrm{a}}$} & \multicolumn{2}{|c|}{$\begin{array}{l}\text { Protective genotypes } \\
\text { (case/control) }\end{array}$} & \multirow{2}{*}{$\begin{array}{c}\text { AOR } \\
(95 \% \mathrm{CI})^{\mathrm{a}}\end{array}$} & \multirow[t]{2}{*}{$P^{\mathbf{a}}$} \\
\hline & TT & $\mathrm{TC} / \mathrm{CC}$ & & & TT & $\mathrm{TC} / \mathrm{CC}$ & & & $0-2$ & 3 & & \\
\hline \multicolumn{13}{|l|}{ Age, month } \\
\hline$\leq 18$ & $146 / 265$ & $198 / 448$ & $0.80(0.62-1.04)$ & 0.098 & $197 / 378$ & $147 / 335$ & $0.84(0.65-1.09)$ & 0.188 & $177 / 327$ & $167 / 386$ & $0.80(0.62-1.03)$ & 0.085 \\
\hline$>18$ & $197 / 336$ & $355 / 684$ & $0.89(0.71-1.10)$ & 0.284 & $302 / 524$ & $250 / 496$ & $0.87(0.71-1.08)$ & 0.205 & $251 / 408$ & $301 / 612$ & $0.80(0.65-0.98)$ & 0.032 \\
\hline \multicolumn{13}{|l|}{ Gender } \\
\hline Female & $156 / 265$ & $250 / 479$ & $0.88(0.69-1.13)$ & 0.325 & $222 / 396$ & $184 / 348$ & $0.94(0.74-1.20)$ & 0.639 & $191 / 318$ & $215 / 426$ & $0.83(0.65-1.06)$ & 0.131 \\
\hline Male & $187 / 336$ & $303 / 653$ & $0.83(0.66-1.04)$ & 0.102 & $277 / 506$ & $213 / 483$ & $0.80(0.65-1.00)$ & 0.05 & $237 / 417$ & $253 / 572$ & $0.77(0.62-0.96)$ & 0.021 \\
\hline \multicolumn{13}{|l|}{ Sites of origin } \\
\hline Adrenal gland & $97 / 601$ & $151 / 1132$ & $0.82(0.62-1.07)$ & 0.143 & $145 / 902$ & $103 / 831$ & $0.76(0.58-1.00)$ & 0.051 & $117 / 735$ & $131 / 998$ & $0.81(0.62-1.06)$ & 0.119 \\
\hline Retroperitoneal & $110 / 601$ & $208 / 1132$ & $0.99(0.77-1.27)$ & 0.93 & $164 / 902$ & $154 / 831$ & $1.02(0.80-1.29)$ & 0.888 & $141 / 735$ & $177 / 998$ & $0.91(0.71-1.16)$ & 0.43 \\
\hline Mediastinum & $85 / 601$ & $128 / 1132$ & $0.80(0.60-1.08)$ & 0.143 & $121 / 902$ & $92 / 831$ & $0.83(0.62-1.11)$ & 0.206 & $111 / 735$ & $102 / 998$ & $0.67(0.51-0.90)$ & 0.007 \\
\hline Others & $46 / 601$ & $59 / 1132$ & $0.69(0.46-1.03)$ & 0.07 & $64 / 902$ & $41 / 831$ & $0.70(0.47-1.05)$ & 0.087 & $52 / 735$ & $53 / 998$ & $0.76(0.51-1.13)$ & 0.178 \\
\hline \multicolumn{13}{|l|}{ Clinical stage } \\
\hline $\mathrm{I}+\mathrm{II}+4 \mathrm{~s}$ & $184 / 601$ & $285 / 1132$ & $0.83(0.67-1.02)$ & 0.08 & $256 / 902$ & $213 / 831$ & $0.91(0.74-1.11)$ & 0.346 & $228 / 735$ & $241 / 998$ & $0.78(0.64-0.96)$ & 0.019 \\
\hline III + IV & $150 / 601$ & $244 / 1132$ & $0.85(0.67-1.07)$ & 0.157 & 230/902 & $164 / 831$ & $0.77(0.62-0.96)$ & 0.022 & $189 / 735$ & 205/998 & $0.77(0.62-0.97)$ & 0.023 \\
\hline
\end{tabular}

Abbreviations: AOR: adjusted odds ratio; $\mathrm{Cl}$ : confidence interval. ${ }^{a}$ Adjusted for age and gender, omitting the corresponding stratify factor.

affected in different time periods. The proliferation activities of SK-N-BE (2) and SK-N-SH cells transfected with siRNA-554 and siRNA-702 were suppressed dramatically at $72 \mathrm{~h}(P<0.05)$. These results indicated that silencing YTHDCl would significantly inhibit the proliferation of NB cells.

\section{Knockdown of YTHDC1 inhibits migration of neuroblastoma cells}

We further investigated the effect of YTHDC1 silencing on the migration of NB cells through wound healing assays (Figure 3A, 3B). These data showed that the migration inhibition rate of SK-N-BE (2) cells transfected with YTHDCl siRNA-488/554/702 reached $18 \%(P>0.05) / 50 \%(P<0.01) / 55 \%(P<$ $0.01)$. However, among SK-N-SH cells, only the cell line transfected with siRNA-554 was obviously suppressed in the migration ability, with an inhibition rate of $43 \%$.

We also investigated the effect of YTHDC1 silencing on the migration of $\mathrm{NB}$ cells through migration assays (Figure 3C, 3D). Migration assay results exhibited that
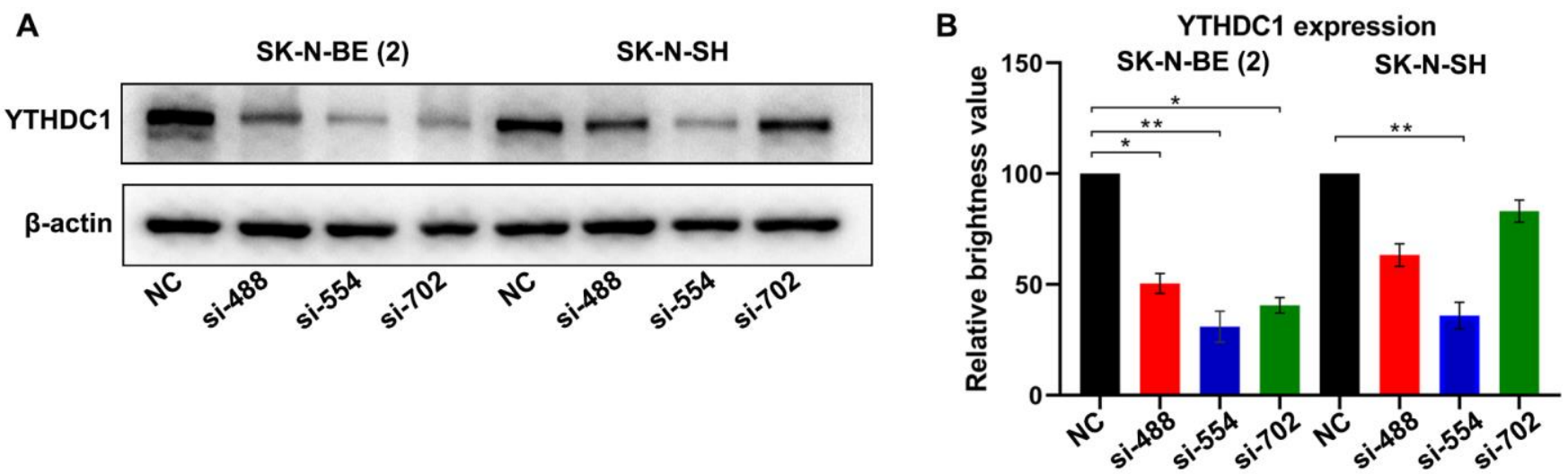

Figure 1. Verification of the silencing effect of different interference sites of YTHDC1 in NB cells. (A) YTHDC1 expression in SKN-BE (2) and SK-N-SH cells transfected with YTHDC1 siRNAs (siRNA-488, siRNA-554, siRNA-702 and siRNA-NC) were detected by Western blot. (B) Quantitative analysis of YTHDC1 expression in SK-N-BE (2) and SK-N-SH cells. 
the migration inhibition rate of SK-N-BE (2) cells transfected with siRNA-488/554/702 reached $51 \% / 70 \% / 63 \%$, relative to the NC group $(P<0.01)$. The migration inhibition rate of SK-N-SH cells transfected with siRNA-488 was $13 \%(P>0.05)$, whereas inhibition rate of cells transfected with siRNA554 and siRNA-702 exceeded $57 \%$ and $40 \%(P<0.01)$.
These results indicate that silencing the expression of YTHDC1 reduces the migration ability of the NB cells.

\section{DISCUSSION}

In this study, we systematically evaluated the associations between common genetic variants in
A

SK-N-BE (2)

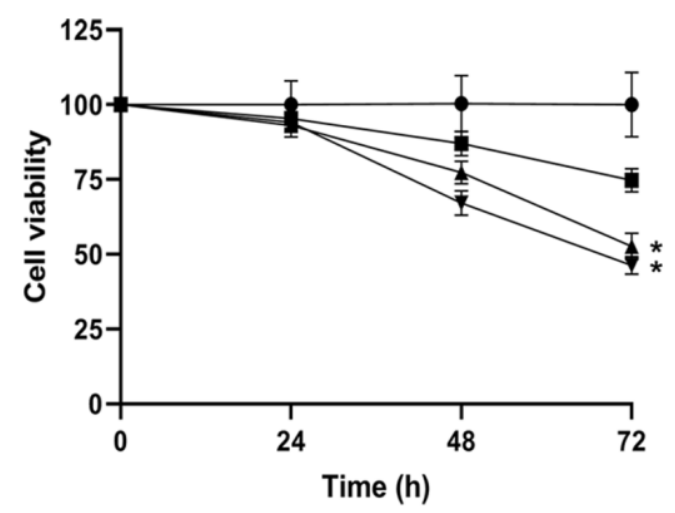

B SK-N-SH

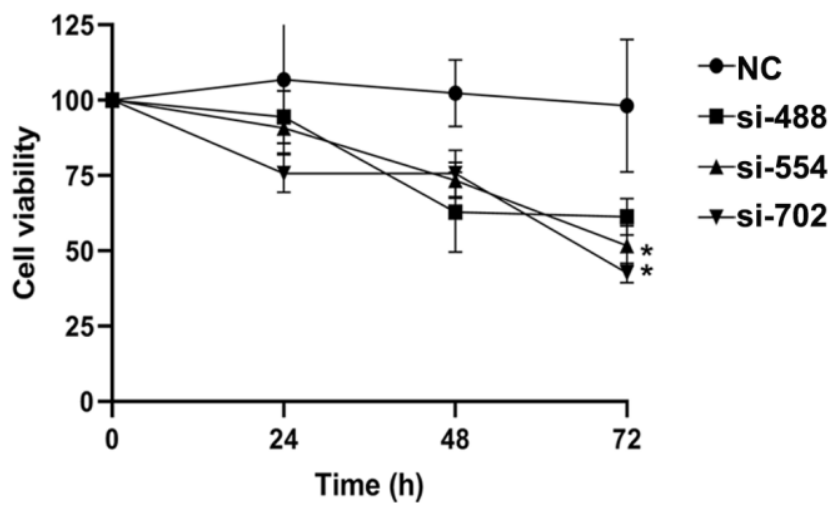

Figure 2. The cell viability of NB transfected with YTHDC1 siRNAs were measured by CCK-8 assay. (A) The cell viability of SK-NBE (2) transfected with YTHDC1 siRNAs at $24 \mathrm{~h}, 48 \mathrm{~h}, 72 \mathrm{~h}$. (B) The SK-N-SH cell viability transfected with YTHDC1 siRNAs. Data were represented as the means \pm SD. ${ }^{*} P<0.05$.

A

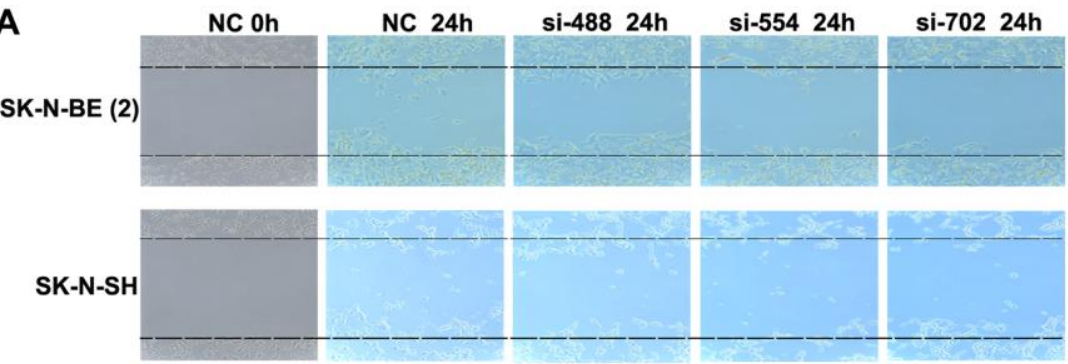

C

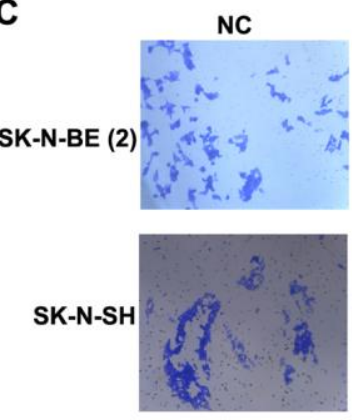

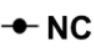

- si-488

\pm si-554

+ si-702
B

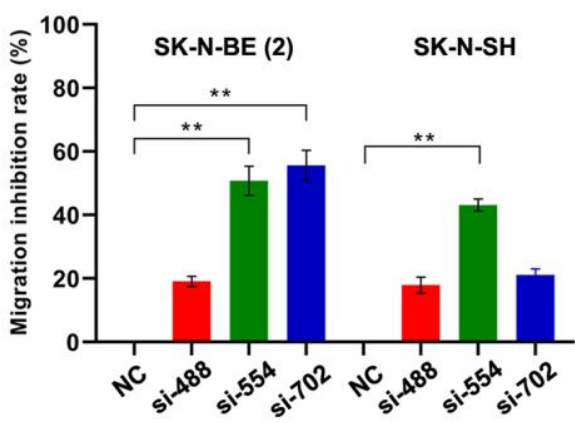

D

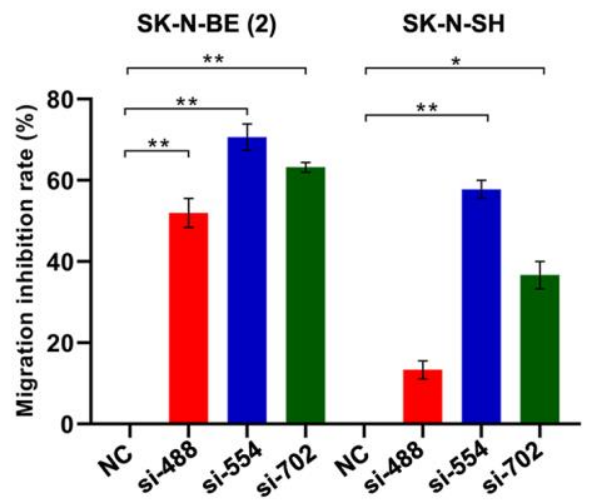

Figure 3. Silencing YTHDC1 inhibited NB cells migration. (A) Migration ability of SK-N-BE (2) and SK-N-SH cells were evaluated by wound healing assay after transfection for $24 \mathrm{~h}$. (B) Quantitative analysis of the migration inhibition rate of SK-N-BE (2) and SK-N-SH cells. (C) Identifying migration ability of SK-N-BE (2) and SK-N-SH cells transfected with YTHDC1 siRNAs for $24 \mathrm{~h}$ by transwell migration assay. (D) Quantitative analysis of SK-N-BE (2) and SK-N-SH cell migration inhibition rate. Data were represented as the means \pm SD, ${ }^{*} P<0.05$, ${ }^{* *} P<0.01$. 
YTHDCl gene and NB risk. We further characterized the YTHDCl functionality in NB via molecular biology experiments. Taken together, we highlighted a NBassociated SNP rs3813832 $\mathrm{T}>\mathrm{C}$ in Chinese population and found that $Y T H D C 1$ acts as a NB oncogene.

RNA $\mathrm{m}^{6} \mathrm{~A}$ methylation is an important epigenetic transcriptional modification and has the highest abundance in eukaryotes [24]. Its methylation balance depends on the synergy between the methyltransferase complex (eraser) and the demethylase (writer), and its function depends on the $\mathrm{m}^{6} \mathrm{~A}$ binding protein (reader) [38]. Under their dynamic regulation, $\mathrm{m}^{6} \mathrm{~A}$ plays an important regulatory role in various physiological processes [39]. Multiple evidence suggested that abnormalities of $\mathrm{m}^{6} \mathrm{~A}$ modification are associated with human carcinogenesis, including hepatoblastoma [40], Wilms tumor [41], bladder cancer [34], and endometrial cancer [42]. The genetic variants in critical $\mathrm{m}^{6} \mathrm{~A}$ modification genes may affect the individual's susceptibility risk to cancers. Zeng et al. [43] genotyped 6 SNPs in FTO gene in samples of 537 breast cancer cases and 537 controls. Of the 6 SNPs analyzed, rs16953002 AA genotype significantly predisposed to a higher breast cancer risk compared to GG genotype, whereas rs1477196 AA genotype was associated with decreased breast cancer risk compared to GG genotype. In addition, Meng et al. [30] demonstrated that SND1 gene rs118049207 could significantly increase the risk of colorectal cancer in the Nanjing and Beijing population of China. Further research revealed the rs118049207 acts as an enhancer of the SND1 intron driven by DMRT3. Compared with adjacent normal tissues, the expression of SND1 mRNA in colorectal tumor tissues increased significantly. They speculated that the genetic variation of $\mathrm{m}^{6} \mathrm{~A}$-modified genes might be a promising predictor of colorectal cancer risk. Polymorphisms in METTL14 gene [44] and METTL3 gene [45] ( $\mathrm{m}^{6} \mathrm{~A}$ methyltransferases) were also reported to be associated with predisposition to neuroblastoma. More recently, our group found that YTHDCl rs2293596 T>C polymorphism predisposed to hepatoblastoma and $Y T H D C 1$ gene polymorphisms may have a cumulative effect on hepatoblastoma risk [46]. We also found that YTHDC1 rs2293595 was associated with a significant inverse association with risk of glioma [33]. The combined effect of YTHDC1 polymorphisms significantly increases Wilms tumor susceptibility [47]. These results indicated that $\mathrm{m}^{6} \mathrm{~A}$ gene variants played an extremely important role in the development of tumors.

The $\mathrm{m}^{6} \mathrm{~A}$ binding proteins (YTHDF1-3, YTHDC1, and YTHDC2) that belong to the YTH domain family are highly conserved in eukaryotic cells [48]. YTHDC1, as an important $\mathrm{m}^{6} \mathrm{~A}$ recognition protein, is involved in the regulation of mRNA shear and mRNA nucleus [26, 49]. Although the function of YTHDC1 is still not fully understood, studies have shown that it plays a regulatory role in pre-mRNA splicing by interacting with SR protein. Based on the combination of transcriptome and PAR-CLIP sequencing technology, Xiao et al. [49] circumstantiated that $\mathrm{m}^{6} \mathrm{~A}$ recruited the precursor mRNA splicing factor SRSF3 through its binding protein YTHDC1 to promote its binding to mRNA, while inhibiting the splicing factor SRSF10 binding to mRNA, thereby it promoted that $\mathrm{m}^{6} \mathrm{~A}$ retains modified exons. In addition, some studies also reported that that YTHDC1 interacted with other splicing factors and could be used as potential tumor suppressors for endometrial cancer [42]. The expression of YTHDC1 has been detected in a panel of prostate cell lines and not in the benign prostate cell lines, indicating that YTHDC1 may function as an oncogene in prostate cancer [50]. These findings indicated that YTHDC1 might play an important role in the process of tumor development.

So far, the association between YTHDCl gene polymorphisms and NB susceptibility is unclear. Therefore, we explore the correlation between YTHDC1 gene polymorphisms and NB susceptibility based on an eight-center case-control study. Our results showed that rs3813832 $\mathrm{T}>\mathrm{C}$ could significantly reduce the risk of NB. In addition, stratified analysis revealed that individuals with 3 protective genotypes contributed to a decreased risk of NB in certain subgroups. Subsequently, we further explored whether the expression of YTHDC1 affected the occurrence and development of NB through cell experiments. Based on CCK-8, cell scratch, and cell migration experiments, we found that silencing YTHDCl would significantly inhibit the proliferation and migration of SK-N-BE (2) and SK-N-SH cells. Among three pairs of siRNA series, the inhibitory ability of siRNA-554 was the strongest, followed by siRNA-702, while the inhibitory ability of siRNA-488 was relatively weak. Combining these siRNA target sequences and the comprehensive analysis of $\mathrm{rs} 3813832 \mathrm{~T}>\mathrm{C}$ polymorphism site, we found that the rs3813832 $\mathrm{T}>\mathrm{C}$ site was located in the coding sequence region of $Y T H D C 1$, and it was just located in the downstream region near siRNA-554. This finding indicated that the rs3813832 $\mathrm{T}>\mathrm{C}$ polymorphic site might reduce the expression of YTHDCl by changing the amino acid composition of YTHDC1, and decrease the risk of individuals suffering from NB. These amino composition changes might affect the pre-mRNA splicing and transport of downstream RNA molecules, and thus ultimately inhibit the proliferation and metastasis of NB. The exact molecular mechanism of YTHDC1 rs3813832 T>C on NB risk is worth further exploring. 
Although this study has made some important discoveries, there are still several limitations. First of all, the subjects of this study were all Han population and could not represent the overall level of the Chinese population. In addition, the number of subjects was not large enough, which limited the statistical ability to some extent. It is necessary to further increase the number of research samples in future research. Finally, the research on YTHDC1 and NB proliferation/metastasis-related molecular mechanisms needs more exploration. Of note, the potential mechanism of how these SNPs impacts NB proliferation/metastasis awaits to be elucidated.

In conclusion, our findings indicated that YTHDC1 rs3813832 $\mathrm{T}>\mathrm{C}$ could significantly reduce the susceptibility of NB. In addition, individuals with multiple protective genotypes were less likely to suffer from NB. Silencing YTHDCl would inhibit the proliferation and migration of NB. The specific role and regulation mechanism of $Y T H D C 1$ rs3813832 $\mathrm{T}>\mathrm{C}$ in the occurrence and development of $\mathrm{NB}$ still needs to be fully elucidated.

\section{MATERIALS AND METHODS}

\section{Study population}

A total of 898 patients with NB and 1734 controls were recruited from eight hospitals in Guangzhou, Zhengzhou, Changsha, Wenzhou, Taiyuan, Xi'an, Kunming, and Shenyang (Supplementary Table 1). All cases were newly diagnosed and confirmed as NB by pathology. Participants without NB were recruited as healthy controls during the same period in the same geographic area. Specific recruitment details and selection criteria have been described in our previous studies [44, 51]. Informed consent forms were obtained from the parents or guardians of all participants. Our study has been approved by the Institutional Review Board of Guangzhou Women and Children's Medical Center (Ethic approve No: 201929300).

\section{Genotyping}

The criteria for choosing potential functional polymorphisms of the YTHDCl gene have been reported minutely in our previous study [46]. The selection criteria were as follows: SNPs are located in the in the 5'- flanking region, exon, 5'- untranslated region (5'UTR), and 3'UTR of $Y T H D C 1$; SNPs should be functional variations predicted by SNPinfo (https://snpinfo.niehs.nih.gov/snpinfo/snpfunc.html); the minor allele frequencies should be $>5 \%$ in Chinese Han population; no significant linkage disequilibrium
(LD) existed between selected SNPs $\left(\mathrm{R}^{2}<0.8\right)$. We first screened out 31 potentially functional SNPs in YTHDC1 via SNPinfo [46]. Among them, rs2293596 T $>C$ and rs223595 $\mathrm{T}>\mathrm{C}$ are located in the $3^{\prime} \mathrm{UTR}$, predicting that they are related to microRNA binding. The rs3813832 $\mathrm{T}>\mathrm{C}$ polymorphism was predicted to contribute to amino acid alteration. LDlink software (https://ldlink.nci.nih.gov) result indicated that there was no significant $\mathrm{LD}\left(\mathrm{R}^{2}<0.8\right)$ among these three selected SNPs $\left(\mathrm{R}^{2}=0.153\right.$ between rs2293596 and rs2293595; $\mathrm{R}^{2}=0.082$ between $\mathrm{rs} 2293596$ and $\mathrm{rs} 3813832 ; \mathrm{R}^{2}=0.537$ between $\mathrm{rs} 2293595$ and rs3813832). Genomic DNA was extracted from the participants' venous blood samples. DNA samples were genotyped for the YTHDC1 SNPs (rs2293596 T>C, rs2293595 $\mathrm{T}>\mathrm{C}$, and rs3813832 $\mathrm{T}>\mathrm{C}$ ) by $\mathrm{ABI} 7900 \mathrm{HT}$ real-time quantitative PCR instrument (Applied Biosystem, USA). In addition, 10\% of DNA samples were chosen for repeated genotyping and the genotyping accuracy rate was $100 \%$.

\section{Cell culture}

Human neuroblastoma cell lines SK-N-BE (2) and SK$\mathrm{N}-\mathrm{SH}$ were purchased from the American Type Culture Collection (ATCC, USA). All cells were cultured in EMEM medium (ATCC, USA) containing $10 \%$ of fetal bovine serum (FBS; Gibco, USA), in an incubator at $37^{\circ} \mathrm{C}$ with $95 \%$ humidity and $5 \% \mathrm{CO}_{2}$.

\section{Cell transfection}

Three siRNAs (siRNA-488, siRNA-554, and siRNA702) targeting YTHDCl gene were designed and synthesized by OBIO Biotechnology Co., Ltd (Shanghai, China). A scrambled siRNA (siRNA-NC) was synthesized as a negative control. All siRNAs sequences were listed in Supplementary Table 2. SK-NBE $(2)$ and SK-N-SH cells $\left(4 \times 10^{5}\right.$ cells/well $)$ were added to 6-well plates for $24 \mathrm{~h}$ in EMEM with $10 \%$ FBS before transfection. SK-N-BE (2) and SK-N-SH cells were transfected with YTHDCl siRNAs in Lipofectamine $^{\mathrm{TM}}$ RNAiMAX Transfection Reagent (Thermo Fisher, USA). After transfection, cells were cultured in the incubator for $24 \mathrm{~h}$ for subsequent experiments.

\section{Cell proliferation assay}

The CCK-8 kit (Dojindo Molecular Technologies, Japan) was used to measure the cell viability. SK-NBE (2) and SK-N-SH cells $\left(4 \times 10^{3}\right.$ cells/well) were transferred to 96 -well plates and then transfected by YTHDCl siRNAs after $24 \mathrm{~h}$. The optical density values at $450 \mathrm{~nm}(\mathrm{OD} 450)$ of SK-N-BE (2) and SK-N$\mathrm{SH}$ cells treatment with $\mathrm{CCK}-8$ reagent after 
transfection for $24 \mathrm{~h}, 48 \mathrm{~h}$, and $72 \mathrm{~h}$ were detected by a microplate reader (Thermo Fisher, USA).

\section{Western blotting}

The specific steps of Western blotting have been described in a previously published article [52]. After the incubation with anti-YTHDC1 antibody (1:1000), anti- $\beta$-actin antibody (1:1000), the membranes were incubated with peroxidase (HRP)-conjugated secondary antibody (1:4000). All the antibodies employed in this study were listed in Supplementary Table 3 . The protein bands were detected using SuperSignal ${ }^{\mathrm{TM}}$ West Femto maximum sensitivity substrate (Thermo Fisher, USA) and a ChemiDOCTM XRS+ imaging system (Bio-rad, USA). The signal intensities of different protein bands were analyzed with ImageJ software (NIH, USA).

\section{Wound healing assay}

SK-N-BE (2) and SK-N-SH cells $\left(2.0 \times 10^{5}\right.$ cells/well $)$ were transferred into 6-well plates and incubated for 24 $\mathrm{h}$ and then transfected with YTHDCl siRNAs. The cell scratches were performed with $10 \mu \mathrm{L}$ pipette tips, and the cells were cultured with Opti-MEM (Gibco, USA) in the incubator. After incubation for $48 \mathrm{~h}$, the cells were imaged with the fluorescence inverted microscope (Leica, Germany). The cell migration distances were calculated by Image-Pro Plus 6.0 software (Media Cybernetics, USA).

\section{Migration assay}

The migration ability of SK-N-BE (2) and SK-N-SH cells transfected with siRNAs were evaluated using transwell assay in the 24-well plates. These cells transfected with siRNAs $\left(2.5 \times 10^{4}\right.$ cells $)$ were seeded into the $8 \mu \mathrm{m}$ transwell upper chamber (BD Biosciences, USA) in $150 \mu \mathrm{L}$ of EMEM basic medium. EMEM medium $(700 \mu \mathrm{L})$ with $10 \%$ FBS was used as a chemo-attractant in the lower chamber. After $24 \mathrm{~h}$, the cells that migrated to the lower surface of chamber were fixed with $70 \%$ absolute ethanol and stained with $0.1 \%$ crystal violet and imaged using the inverted microscope (Leica, Germany).

\section{Statistical analysis}

In this study, statistical analysis was performed by SAS 9.4 software (SAS Institute Inc, USA). The distribution of sample characteristics between all NB cases and the control group was verified using a two-sided $\chi^{2}$ test. The goodness-of-fit chi-square test was used to test whether the genotype frequency in the control conforms to HWE. Based on unconditional logistic regression analysis, the AOR and $95 \% \mathrm{CI}$ were calculated to assess the association between YTHDC1 polymorphisms and NB risk. In addition, the cell functional experiments were performed independently for three times and the relevant data obtained were displayed with the mean \pm SD. The SPSS 20.0 software (IBM, USA) was used for statistical analysis based on the least difference test by one-way analysis of variance (ANOVA). The standard with statistical significance were ${ }^{*} P$ value $<0.05$ and ${ }^{* *} P$ value $<0.01$.

\section{Abbreviations}

NB: neuroblastoma; GWAS: genome-wide association study; SNP: single nucleotide polymorphism; $\mathrm{m}^{6} \mathrm{~A}$ : N6methyladenosine; YTHDC1: YTH domain contains protein 1; HWE: Hardy-Weinberg equilibrium; AOR: adjusted odds ratio; CI: confidence interval; UTR: untranslated region; LD: linkage disequilibrium; ATCC: American Type Culture Collection; FBS: fetal bovine serum; ANOVA: analysis of variance.

\section{AUTHOR CONTRIBUTIONS}

All authors contributed significantly to this work. Y. Li, T. Lu, J. Wang, Z. Zhuo, L. Miao, Z. Yang, J. Zhang, J. Cheng, H. Zhou, S. Li, L. Li, A. Li and J. He performed the research study and collected the samples and data; J. $\mathrm{He}$ analyzed the data; A. Li and J. He conceptualized and designed the research study; Y. Li, T. Lu, Z. Zhuo, A. Li and J. He wrote the paper; J. He prepared all the Tables; T. Lu, Z. Zhuo and L. Miao prepared all the Figures. All authors reviewed the manuscript. In addition, all authors have read and approved the manuscript.

\section{CONFLICTS OF INTEREST}

The authors declare no conflicts of interest related to this study.

\section{FUNDING}

This study was supported by grants from National Natural Science Foundation of China (No. 82173593, 82002636, 82002635), Natural Science Foundation of Guangdong Province (No. 2019A1515010360), Natural Science Foundation Project of Hunan Province (No. 2018JJ2210, 2020SK50501), China Postdoctoral Science Foundation (No. 2020T130132, 2020M682668).

\section{REFERENCES}

1. Nakagawara A, Li Y, Izumi H, Muramori K, Inada $\mathrm{H}$, Nishi M. Neuroblastoma. Jpn J Clin Oncol. 2018; 48:214-41. 
https://doi.org/10.1093/iico/hyx176

PMID:29378002

2. Maris JM, Hogarty MD, Bagatell R, Cohn SL. Neuroblastoma. Lancet. 2007; 369:2106-20. https://doi.org/10.1016/S0140-6736(07)60983-0 PMID:17586306

3. Hero B, Simon T, Spitz R, Ernestus K, Gnekow AK, Scheel-Walter HG, Schwabe D, Schilling FH, BenzBohm G, Berthold F. Localized infant neuroblastomas often show spontaneous regression: results of the prospective trials NB95-S and NB97. J Clin Oncol. 2008; 26:1504-10.

https://doi.org/10.1200/JCO.2007.12.3349 PMID:18349403

4. Matthay KK, Reynolds CP, Seeger RC, Shimada H, Adkins ES, Haas-Kogan D, Gerbing RB, London WB, Villablanca JG. Long-term results for children with high-risk neuroblastoma treated on a randomized trial of myeloablative therapy followed by 13-cisretinoic acid: a children's oncology group study. J Clin Oncol. 2009; 27:1007-13.

https://doi.org/10.1200/JCO.2007.13.8925

PMID:19171716

5. He X, Qin C, Zhao Y, Zou L, Zhao H, Cheng C. Gene signatures associated with genomic aberrations predict prognosis in neuroblastoma. Cancer Commun (Lond). 2020; 40:105-18.

https://doi.org/10.1002/cac2.12016

PMID:32237073

6. Yue ZX, Xing TY, Gao C, Liu SG, Zhao W, Zhao Q, Wang $X S$, Jin M, Ma XL. Chromosome band 11q23 deletion predicts poor prognosis in bone marrow metastatic neuroblastoma patients without MYCN amplification. Cancer Commun (Lond). 2019; 39:68. https://doi.org/10.1186/s40880-019-0409-1 PMID: $\underline{31685009}$

7. Bourdeaut F, Trochet D, Janoueix-Lerosey I, Ribeiro A, Deville A, Coz C, Michiels JF, Lyonnet S, Amiel J, Delattre $O$. Germline mutations of the paired-like homeobox 2B (PHOX2B) gene in neuroblastoma. Cancer Lett. 2005; 228:51-8.

https://doi.org/10.1016/i.canlet.2005.01.055 PMID:15949893

8. Mossé $Y P$, Laudenslager $M$, Longo $L$, Cole KA, Wood A, Attiyeh EF, Laquaglia MJ, Sennett R, Lynch JE, Perri P, Laureys G, Speleman F, Kim C, et al. Identification of ALK as a major familial neuroblastoma predisposition gene. Nature. 2008; 455:930-5. https://doi.org/10.1038/nature07261 PMID: 18724359

9. Matthay KK, Maris JM, Schleiermacher G, Nakagawara A, Mackall CL, Diller L, Weiss WA.
Neuroblastoma. Nat Rev Dis Primers. 2016; 2:16078.

https://doi.org/10.1038/nrdp.2016.78

PMID:27830764

10. Patton T, Olshan AF, Neglia JP, Castleberry RP, Smith J. Parental exposure to medical radiation and neuroblastoma in offspring. Paediatr Perinat Epidemiol. 2004; 18:178-85.

https://doi.org/10.1111/i.1365-3016.2004.00554.x

PMID:15130156

11. Han W, Zhou Y, Zhong R, Wu C, Song R, Liu L, Zou L, Qiao Y, Zhai K, Chang J, Huang L, Liu L, Lu X, et al. Functional polymorphisms in FAS/FASL system increase the risk of neuroblastoma in Chinese population. PLoS One. 2013; 8:e71656.

https://doi.org/10.1371/journal.pone.0071656 PMID:23951214

12. Tonini GP, Capasso M. Genetic predisposition and chromosome instability in neuroblastoma. Cancer Metastasis Rev. 2020; 39:275-85. https://doi.org/10.1007/s10555-020-09843-4 PMID:31927719

13. Capasso M, Devoto M, Hou C, Asgharzadeh S, Glessner JT, Attiyeh EF, Mosse YP, Kim C, Diskin SJ, Cole KA, Bosse K, Diamond M, Laudenslager M, et al. Common variations in BARD1 influence susceptibility to highrisk neuroblastoma. Nat Genet. 2009; 41:718-23.

https://doi.org/10.1038/ng.374

PMID: 19412175

14. Wang K, Diskin SJ, Zhang H, Attiyeh EF, Winter C, Hou C, Schnepp RW, Diamond M, Bosse K, Mayes PA, Glessner J, Kim C, Frackelton E, et al. Integrative genomics identifies LMO1 as a neuroblastoma oncogene. Nature. 2011; 469:216-20.

https://doi.org/10.1038/nature09609 PMID:21124317

15. Diskin SJ, Capasso M, Schnepp RW, Cole KA, Attiyeh EF, Hou C, Diamond M, Carpenter EL, Winter C, Lee H, Jagannathan J, Latorre $\mathrm{V}$, Iolascon $\mathrm{A}$, et al. Common variation at $6 q 16$ within HACE1 and LIN28B influences susceptibility to neuroblastoma. Nat Genet. 2012; 44:1126-30.

https://doi.org/10.1038/ng.2387 PMID:22941191

16. Diskin SJ, Capasso $M$, Diamond $M$, Oldridge DA, Conkrite K, Bosse KR, Russell MR, Iolascon A, Hakonarson H, Devoto $M$, Maris JM. Rare variants in TP53 and susceptibility to neuroblastoma. J Natl Cancer Inst. 2014; 106:dju047.

https://doi.org/10.1093/jnci/dju047

PMID:24634504

17. Russell MR, Penikis A, Oldridge DA, AlvarezDominguez JR, McDaniel L, Diamond M, Padovan O, 
Raman P, Li Y, Wei JS, Zhang S, Gnanchandran J, Seeger R, et al. CASC15-S is a Tumor Suppressor IncRNA at the 6p22 Neuroblastoma Susceptibility Locus. Cancer Res. 2015; 75:3155-66.

https://doi.org/10.1158/0008-5472.CAN-14-3613 PMID:26100672

18. McDaniel LD, Conkrite KL, Chang X, Capasso $M$, Vaksman Z, Oldridge DA, Zachariou A, Horn M, Diamond $M$, Hou C, Iolascon A, Hakonarson $H$, Rahman N, et al. Common variants upstream of MLF1 at $3 q 25$ and within $\mathrm{CPZ}$ at $4 \mathrm{p} 16$ associated with neuroblastoma. PLoS Genet. 2017; 13:e1006787.

https://doi.org/10.1371/journal.pgen.1006787 PMID:28545128

19. Capasso M, McDaniel LD, Cimmino F, Cirino A, Formicola D, Russell MR, Raman P, Cole KA, Diskin SJ. The functional variant rs34330 of CDKN1B is associated with risk of neuroblastoma. J Cell Mol Med. 2017; 21:3224-30.

https://doi.org/10.1111/jcmm.13226

PMID:28667701

20. Avitabile M, Lasorsa VA, Cantalupo S, Cardinale A, Cimmino F, Montella A, Capasso D, Haupt R, Amoroso L, Garaventa A, Quattrone A, Corrias MV, Iolascon A, Capasso M. Association of PARP1 polymorphisms with response to chemotherapy in patients with highrisk neuroblastoma. J Cell Mol Med. 2020; 24:407281.

https://doi.org/10.1111/jcmm.15058

PMID:32103589

21. Olivera GG, Yáñez $Y$, Gargallo $P$, Sendra L, Aliño SF, Segura V, Sanz MÁ, Cañete A, Castel V, Font De Mora J, Hervás D, Berlanga P, Herrero MJ. MTHFR and VDR Polymorphisms Improve the Prognostic Value of MYCN Status on Overall Survival in Neuroblastoma Patients. Int J Mol Sci. 2020; 21:2714.

https://doi.org/10.3390/ijms21082714

PMID: 32295184

22. Avitabile $M$, Succoio $M$, Testori A, Cardinale $A$, Vaksman Z, Lasorsa VA, Cantalupo S, Esposito M, Cimmino F, Montella A, Formicola D, Koster J, Andreotti $V$, et al. Neural crest-derived tumor neuroblastoma and melanoma share 1 p13.2 as susceptibility locus that shows a long-range interaction with the SLC16A1 gene. Carcinogenesis. 2020; 41:284-95.

https://doi.org/10.1093/carcin/bgz153

PMID:31605138

23. Testori A, Lasorsa VA, Cimmino F, Cantalupo S, Cardinale A, Avitabile M, Limongelli G, Russo MG, Diskin S, Maris J, Devoto M, Keavney B, Cordell HJ, et al. Exploring Shared Susceptibility between Two Neural Crest Cells Originating Conditions:
Neuroblastoma and Congenital Heart Disease. Genes (Basel). 2019; 10:663.

https://doi.org/10.3390/genes10090663

PMID:31480262

24. Meyer KD, Saletore Y, Zumbo P, Elemento O, Mason $\mathrm{CE}$, Jaffrey SR. Comprehensive analysis of mRNA methylation reveals enrichment in 3' UTRs and near stop codons. Cell. 2012; 149:1635-46.

https://doi.org/10.1016/i.cell.2012.05.003

PMID:22608085

25. Zhao W, Qi X, Liu L, Ma S, Liu J, Wu J. Epigenetic Regulation of $\mathrm{m}^{6} \mathrm{~A}$ Modifications in Human Cancer. Mol Ther Nucleic Acids. 2020; 19:405-12. https://doi.org/10.1016/j.omtn.2019.11.022 PMID:31887551

26. Zhao BS, Roundtree IA, He C. Post-transcriptional gene regulation by mRNA modifications. Nat Rev Mol Cell Biol. 2017; 18:31-42.

https://doi.org/10.1038/nrm.2016.132 PMID:27808276

27. Yang Y, Hsu PJ, Chen YS, Yang YG. Dynamic transcriptomic $\mathrm{m}^{6} \mathrm{~A}$ decoration: writers, erasers, readers and functions in RNA metabolism. Cell Res. 2018; 28:616-24.

https://doi.org/10.1038/s41422-018-0040-8 PMID:29789545

28. Zhou C, Zhang Z, Zhu X, Qian G, Zhou Y, Sun Y, Yu W, Wang J, Lu H, Lin F, Shen Z, Zheng S. N6Methyladenosine modification of the TRIM7 positively regulates tumorigenesis and chemoresistance in osteosarcoma through ubiquitination of BRMS1. EBioMedicine. 2020; 59:102955.

https://doi.org/10.1016/j.ebiom.2020.102955 PMID:32853985

29. Zhang S, Zhao BS, Zhou A, Lin K, Zheng S, Lu Z, Chen Y, Sulman EP, Xie K, Bögler O, Majumder S, He C, Huang S. $\mathrm{m}^{6} \mathrm{~A}$ Demethylase ALKBH5 Maintains Tumorigenicity of Glioblastoma Stem-like Cells by Sustaining FOXM1 Expression and Cell Proliferation Program. Cancer Cell. 2017; 31:591-606.e6. https://doi.org/10.1016/i.ccell.2017.02.013 PMID:28344040

30. Meng Y, Li S, Gu D, Xu K, Du M, Zhu L, Chu H, Zhang Z, Wu $Y$, Fu Z, Wang M. Genetic variants in m6A modification genes are associated with colorectal cancer risk. Carcinogenesis. 2020; 41:8-17.

https://doi.org/10.1093/carcin/bgz165 PMID: $\underline{31579913}$

31. Li Z, Weng $H$, Su R, Weng $X$, Zuo Z, Li C, Huang $H$, Nachtergaele S, Dong L, Hu C, Qin X, Tang L, Wang Y, et al. FTO Plays an Oncogenic Role in Acute Myeloid 
Leukemia as a $\mathrm{N}^{6}$-Methyladenosine RNA Demethylase. Cancer Cell. 2017; 31:127-41.

https://doi.org/10.1016/j.ccell.2016.11.017

PMID:28017614

32. Yang $Z$, Jiang $X$, Li $D$, Jiang $X$. HBXIP promotes gastric cancer via METTL3-mediated MYC mRNA m6A modification. Aging (Albany NY). 2020; 12:24967-82. https://doi.org/10.18632/aging.103767 PMID: 33048840

33. He J, Yuan L, Lin H, Lin A, Chen H, Luo A, Zhuo Z, Liu X. Genetic variants in $\mathrm{m}^{6} \mathrm{~A}$ modification core genes are associated with glioma risk in Chinese children. Mol Ther Oncolytics. 2021; 20:199-208.

https://doi.org/10.1016/j.omto.2020.12.013 PMID:33665358

34. Han J, Wang JZ, Yang $X, Y u$, Zhou R, Lu HC, Yuan WB, Lu JC, Zhou ZJ, Lu Q, Wei JF, Yang H. METTL3 promote tumor proliferation of bladder cancer by accelerating pri-miR221/222 maturation in m6Adependent manner. Mol Cancer. 2019; 18:110. https://doi.org/10.1186/s12943-019-1036-9 PMID: 31228940

35. Liu $H$, Gu J, Jin Y, Yuan Q, Ma G, Du M, Ge Y, Qin C, Lv Q, Fu G, Wang M, Chu H, Yuan L, Zhang Z. Genetic variants in N6-methyladenosine are associated with bladder cancer risk in the Chinese population. Arch Toxicol. 2021; 95:299-309. https://doi.org/10.1007/s00204-020-02911-2 PMID: $\underline{32964246}$

36. Fu Y, Dominissini D, Rechavi G, He C. Gene expression regulation mediated through reversible $m^{6} \mathrm{~A}$ RNA methylation. Nat Rev Genet. 2014; 15:293-306.

https://doi.org/10.1038/nrg3724 PMID:24662220

37. Liu N, Dai Q, Zheng G, He C, Parisien M, Pan T. N(6)methyladenosine-dependent RNA structural switches regulate RNA-protein interactions. Nature. 2015; 518:560-4.

https://doi.org/10.1038/nature14234 PMID:25719671

38. Meyer KD, Jaffrey SR. Rethinking $m^{6} \mathrm{~A}$ Readers, Writers, and Erasers. Annu Rev Cell Dev Biol. 2017; 33:319-42.

https://doi.org/10.1146/annurev-cellbio-100616$\underline{060758}$

PMID:28759256

39. Niu Y, Zhao X, Wu YS, Li MM, Wang XJ, Yang YG. N6methyl-adenosine (m6A) in RNA: an old modification with a novel epigenetic function. Genomics Proteomics Bioinformatics. 2013; 11:8-17. https://doi.org/10.1016/i.gpb.2012.12.002 PMID:23453015
40. Liu L, Wang J, Sun G, Wu Q, Ma J, Zhang X, Huang N, Bian Z, Gu S, Xu M, Yin M, Sun F, Pan Q. Correction to: m6A mRNA methylation regulates CTNNB1 to promote the proliferation of hepatoblastoma. Mol Cancer. 2020; 19:24.

https://doi.org/10.1186/s12943-020-1136-6

PMID:32019547

41. Hua RX, Liu J, Fu W, Zhu J, Zhang J, Cheng J, Li S, Zhou $\mathrm{H}, \mathrm{Xia} \mathrm{H}, \mathrm{He} \mathrm{J}$, Zhuo Z. ALKBH5 gene polymorphisms and Wilms tumor risk in Chinese children: A fivecenter case-control study. J Clin Lab Anal. 2020; 34:e23251.

https://doi.org/10.1002/jcla.23251

PMID:32091154

42. Zhang $B$, zur Hausen $A$, Orlowska-Volk $M$, Jäger $M$, Bettendorf H, Stamm S, Hirschfeld M, Yiqin O, Tong X, Gitsch G, Stickeler E. Alternative splicing-related factor YT521: an independent prognostic factor in endometrial cancer. Int J Gynecol Cancer. 2010; 20:492-9.

https://doi.org/10.1111/IGC.0b013e3181d66ffe PMID:20686370

43. Zeng X, Ban Z, Cao J, Zhang W, Chu T, Lei D, Du Y. Association of FTO Mutations with Risk and Survival of Breast Cancer in a Chinese Population. Dis Markers. 2015; 2015:101032.

https://doi.org/10.1155/2015/101032

PMID:26146447

44. Zhuo Z, Lu H, Zhu J, Hua RX, Li Y, Yang Z, Zhang J, Cheng J, Zhou H, Li S, Li L, Xia H, He J. METTL14 Gene Polymorphisms Confer Neuroblastoma Susceptibility: An Eight-Center Case-Control Study. Mol Ther Nucleic Acids. 2020; 22:17-26.

https://doi.org/10.1016/j.omtn.2020.08.009 PMID: 32891980

45. Bian J, Zhuo Z, Zhu J, Yang Z, Jiao Z, Li Y, Cheng J, Zhou $\mathrm{H}$, Li S, Li L, He J, Liu Y. Association between METTL3 gene polymorphisms and neuroblastoma susceptibility: A nine-centre case-control study. J Cell Mol Med. 2020; 24:9280-6.

https://doi.org/10.1111/jcmm.15576

PMID: $\underline{32615646}$

46. Chen H, Li Y, Li L, Zhu J, Yang Z, Zhang J, Li S, Xin Y, Xia $\mathrm{H}$, He J. YTHDC1 gene polymorphisms and hepatoblastoma susceptibility in Chinese children: A seven-center case-control study. J Gene Med. 2020; 22:e3249.

https://doi.org/10.1002/igm.3249

PMID:32729171

47. Lin A, Hua RX, Zhou M, Fu W, Zhang J, Zhou H, Li S, Cheng J, Zhu J, Xia H, Liu G, He J. YTHDC1 gene polymorphisms and Wilms tumor susceptibility in Chinese children: A five-center case-control study. Gene. 2021; 783:145571. 
https://doi.org/10.1016/i.gene.2021.145571

PMID:33737126

48. Yang $\mathrm{N}$, Ying $\mathrm{P}$, Tian J, Wang $X$, Mei $S$, Zou D, Peng $X$, Gong Y, Yang Y, Zhu Y, Ke J, Zhong R, Chang J, Miao X. Genetic variants in $\mathrm{m} 6 \mathrm{~A}$ modification genes are associated with esophageal squamous-cell carcinoma in the Chinese population. Carcinogenesis. 2020; 41:761-8.

https://doi.org/10.1093/carcin/bgaa012

PMID: $\underline{32047883}$

49. Xiao W, Adhikari S, Dahal U, Chen YS, Hao YJ, Sun BF, Sun HY, Li A, Ping XL, Lai WY, Wang X, Ma HL, Huang $C M$, et al. Nuclear m(6)A Reader YTHDC1 Regulates mRNA Splicing. Mol Cell. 2016; 61:507-19.

https://doi.org/10.1016/i.molcel.2016.01.012

PMID:26876937

50. Luxton HJ, Simpson BS, Mills IG, Brindle NR, Ahmed Z, Stavrinides V, Heavey S, Stamm S, Whitaker HC. The Oncogene Metadherin Interacts with the Known Splicing Proteins YTHDC1, Sam68 and T-STAR and Plays a Novel Role in Alternative mRNA Splicing. Cancers (Basel). 2019; 11:1233.

https://doi.org/10.3390/cancers11091233

PMID:31450747
51. Zhuo Z, Zhou C, Fang $Y$, Zhu J, Lu $H$, Zhou $H$, Wu H, Wang $\mathrm{Y}, \mathrm{He} \mathrm{J}$. Correlation between the genetic variants of base excision repair (BER) pathway genes and neuroblastoma susceptibility in eastern Chinese children. Cancer Commun (Lond). 2020; 40:641-6.

https://doi.org/10.1002/cac2.12088

PMID: $\underline{2780923}$

52. Lu T, Wu B, Yu Y, Zhu W, Zhang S, Zhang Y, Guo J, Deng $N$. Blockade of ONECUT2 expression in ovarian cancer inhibited tumor cell proliferation, migration, invasion and angiogenesis. Cancer Sci. 2018; 109:2221-34.

https://doi.org/10.1111/cas.13633

PMID:29737581 


\section{SUPPLEMENTARY MATERIALS}

\section{Supplementary Tables}

Supplementary Table 1. Frequency distribution of selected characteristics in neuroblastoma cases and cancer-free controls.

\begin{tabular}{|c|c|c|c|c|c|}
\hline \multirow{3}{*}{ Variables } & \multicolumn{5}{|c|}{ Combined subjects (8 Centers) } \\
\hline & \multicolumn{2}{|c|}{ Cases $(n=898)$} & \multicolumn{2}{|c|}{ Controls $(n=1734)$} & \multirow[t]{2}{*}{$P^{\mathbf{a}}$} \\
\hline & No. & $\%$ & No. & $\%$ & \\
\hline Age range, month & \multicolumn{2}{|c|}{$0.00-176.00$} & \multicolumn{2}{|c|}{$0.004-156.00$} & 0.155 \\
\hline Mean \pm SD & \multicolumn{2}{|c|}{$33.11 \pm 28.07$} & \multicolumn{2}{|c|}{$30.41 \pm 24.90$} & \\
\hline$\leq 18$ & 344 & 38.31 & 714 & 41.18 & \\
\hline$>18$ & 554 & 61.69 & 1020 & 58.82 & \\
\hline Gender & & & & & 0.236 \\
\hline Female & 407 & 45.32 & 744 & 42.91 & \\
\hline Male & 491 & 54.68 & 990 & 57.09 & \\
\hline \multicolumn{6}{|l|}{ INSS stages } \\
\hline I & 310 & 34.52 & l & l & \\
\hline II & 160 & 17.82 & I & l & \\
\hline III & 163 & 18.15 & I & l & \\
\hline IV & 231 & 25.72 & I & l & \\
\hline $4 \mathrm{~s}$ & 18 & 2.00 & l & l & \\
\hline NA & 16 & 1.78 & I & l & \\
\hline \multicolumn{6}{|l|}{ Sites of origin } \\
\hline Adrenal gland & 248 & 27.62 & I & l & \\
\hline Retroperitoneal region & 319 & 35.52 & I & l & \\
\hline Mediastinum & 214 & 23.83 & I & l & \\
\hline Other region & 105 & 11.69 & l & l & \\
\hline NA & 12 & 1.34 & l & l & \\
\hline
\end{tabular}

Abbreviation: SD: standard deviation. ${ }^{\mathrm{a}} \mathrm{Two}-\mathrm{sided} \chi^{2}$ test for distributions between neuroblastoma cases and cancer-free controls.

Supplementary Table 2. Target sites and sequences of YTHDC1 siRNAs.

\begin{tabular}{lc}
\hline siRNA names & Sequences $\left(\mathbf{5}^{\prime}\right.$-3') \\
\hline YTHDC1 siRNA-488 & CGAAUGGAAUCUACUGAUATT \\
& UAUCAGUAGAUUCCAUUCGTT \\
YTHDC1 siRNA-554 & CCACUGAGCUCAUCUGUUATT \\
& UAACAGAUGAGCUCAGUGGTT \\
YTHDC1 siRNA-702 & CCAGAGAACCUUAUAAGAATT \\
& UUCUUAUAAGGUUCUCUGGTT \\
YTHDC1 siRNA-NC & UUCUCCGAACGUGUCACGUTT \\
& ACGUGACACGUUCGGAGAATT \\
\hline
\end{tabular}

Abbreviation: NC: scrambled control. 
Supplementary Table 3. Antibodies used.

\begin{tabular}{lcc}
\hline Antibodies & Company & Item number \\
\hline anti-YTHDC1 & Abcam & Cat\#ab122340 \\
anti- $\beta$-actin & Cell Signaling Technology & Cat\#4970S \\
HRP-conjugated goat anti-rabbit IgG & Cell Signaling Technology & Cat\#7074P2 \\
\hline
\end{tabular}

